\title{
A Detailed Study of the Nanocasting Process by In Situ X-Ray Scattering and Diffraction
}

Motolani Sakeye, ${ }^{1}$ Sebastian Ziller, ${ }^{2}$ Heinz Amenitsch, ${ }^{3}$ Mika Lindén, ${ }^{2}$ and Jan-Henrik Smått ${ }^{1, *}$

${ }^{1}$ Laboratory of Physical Chemistry and Center for Functional Materials, Åbo Akademi University, Porthansgatan 3-5, 20500 Turku, Finland.

${ }^{2}$ Inorganic Chemistry II, University of Ulm, Albert-Einstein-Allee 11, 89031 Ulm, Germany.

${ }^{3}$ Institute for Inorganic Chemistry, Graz University of Technology, Stremayrgasse 9/V, A-8010 Graz, Austria.

* To whom correspondence should be addressed: jsmatt@abo.fi, phone: +358 2215 4623, fax: +358 2 2330228

\section{Supporting Information}




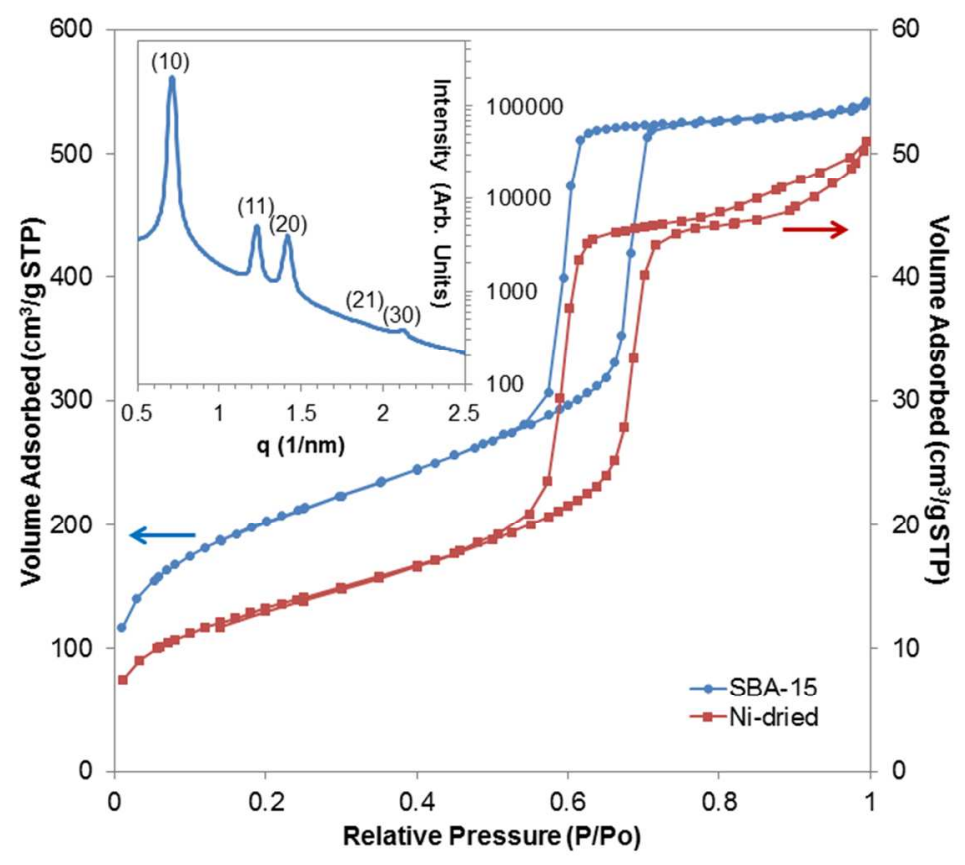

Figure S1. Nitrogen physisorption isotherms of the starting SBA-15 template and the Ni-dried sample. Inset: Small angle XRD pattern of the pristine SBA-15 material. 
Table S1. Textural properties extracted from the nitrogen physisorption isotherms.

\begin{tabular}{|l|c|c|c|c|c|}
\hline Sample & $\begin{array}{c}\text { BET surface } \\
\text { area }\left(\mathrm{m}^{2} / \mathrm{g}\right)\end{array}$ & $\mathrm{V}_{\mathrm{IP}}{ }^{a}\left(\mathrm{~cm}^{3} / \mathrm{g}\right)$ & $\mathrm{V}_{\mathrm{PP}}{ }^{b}\left(\mathrm{~cm}^{3} / \mathrm{g}\right)$ & $\mathrm{V}_{\mathrm{TP}}{ }^{c}\left(\mathrm{~cm}^{3} / \mathrm{g}\right)$ & $\begin{array}{c}\text { Pore width } \\
(\mathrm{nm})^{d}\end{array}$ \\
\hline SBA-15 & 729 & 0.133 & 0.662 & 0.829 & 6.8 \\
\hline Ni-dried & 48 & 0.001 & 0.065 & 0.076 & 6.9 \\
\hline Ni-140-Air & 17 & 0.001 & 0.021 & 0.026 & 6.8 \\
\hline Ni-200-Air & 129 & 0.022 & 0.122 & 0.154 & 6.8 \\
\hline Ni-300-Air & 407 & 0.094 & 0.303 & 0.432 & 6.8 \\
\hline Ni-500-Air & 382 & 0.083 & 0.298 & 0.419 & 6.8 \\
\hline Ni-140-He & 38 & 0.001 & 0.053 & 0.057 & 6.8 \\
\hline Ni-200-He & 118 & 0.013 & 0.130 & 0.144 & 6.7 \\
\hline Ni-300-He & 420 & 0.117 & 0.250 & 0.407 & 6.7 \\
\hline Ni-500-He & 414 & 0.106 & 0.283 & 0.421 & 6.8 \\
\hline Ni-500-Air-R & 79 & 0.026 & 0.033 & 0.111 & $3-10$ \\
\hline Ni-500-He-R & 119 & 0.038 & 0.049 & 0.166 & $3-10$ \\
\hline
\end{tabular}

${ }^{a}$ Pores smaller than $5 \mathrm{~nm}$ in the DFT cumulative pore size distribution plot.

${ }^{b}$ Pores between 5 and $8 \mathrm{~nm}$ in the DFT cumulative pore size distribution plot.

${ }^{c}$ Deduced from the nitrogen adsorbed at $\mathrm{P} / \mathrm{P}_{0}=0.98$.

${ }^{d}$ NL-DFT cylindrical pore model (adsorption branch). 

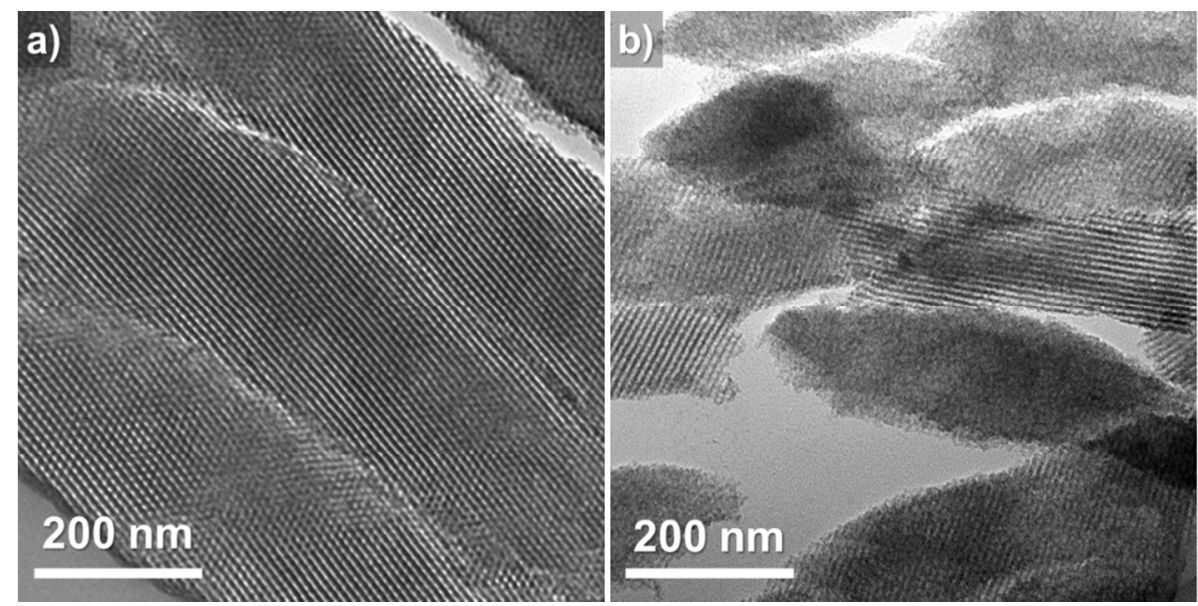

Figure S2. TEM images of a) the starting SBA-15 material, b) the dried SBA-15/nickel salt composite.

The TEM image of the pristine SBA-15 sample displays a well-ordered 2-D hexagonal pore structure viewed along the pore channels. A similar structure can also be see for the Ni-dried sample (Figure $\mathrm{S} 2 \mathrm{~b})$. However, due to mostly filled mesopores, the contrast between the mesopores and the pore walls is clearly lower than for the SBA-15 template. Furthermore, no distinct particles or empty sections can be seen inside the pore channels, which indicates that the pores are evenly filled. 
a)

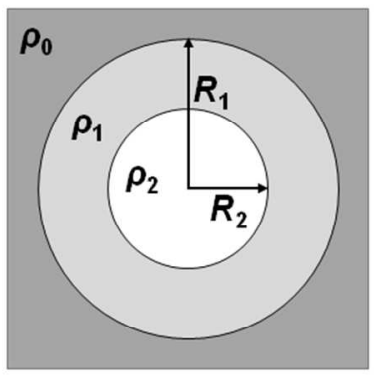

b)

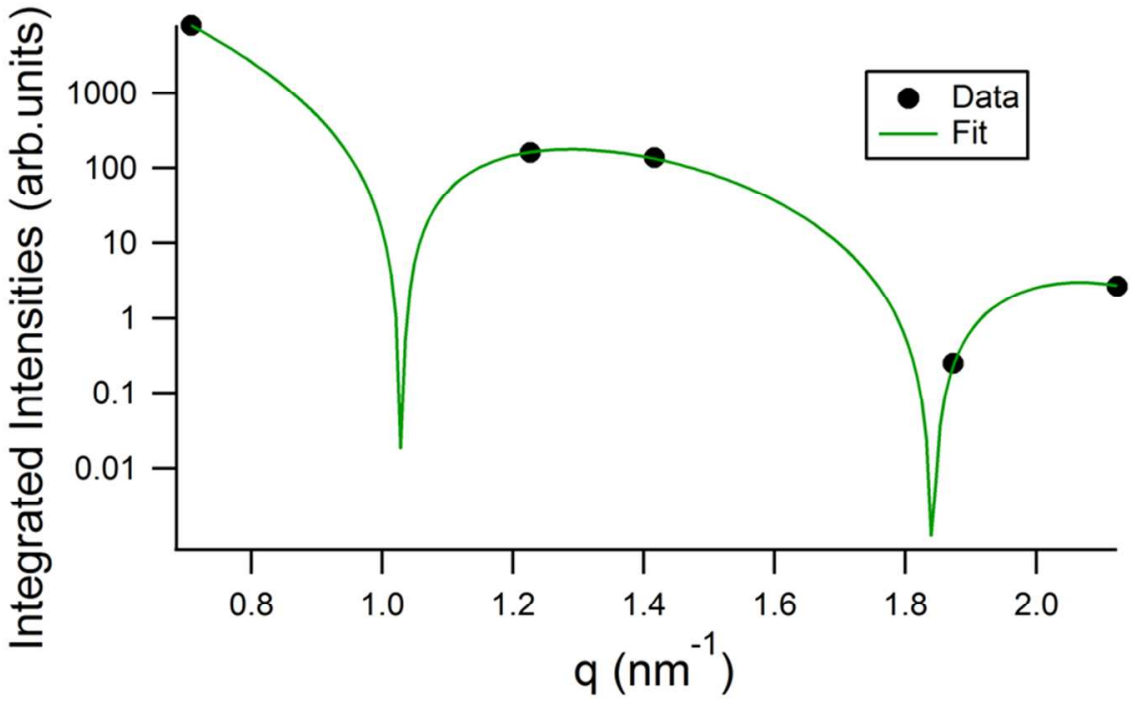

Figure S3. a) Model of the SBA-15 pore structure with three electron density levels $\left(\rho_{0}=\right.$ dense silica matrix $=0.66 \mathrm{e}^{-} / \AA^{3}, \rho_{1}=$ microporous corona, and $\rho_{2}=$ the empty mesopore $\left.=0\right)$. b) Experimental integrated intensities of the first five diffraction peaks and the corresponding model fit for the pristine SBA-15 sample.

In order to investigate the bimodal pore structure of the SBA-15 template in more detail, we used a structural model involving three levels of electron densities to fit the integrated intensities of the (10), (11), (20), (21), and (30) diffraction peaks based on the work by Zickler et al. (see Figure S3a). ${ }^{\text {S1 }}$ First, the intensities and positions of the Bragg reflections were determined by Gaussian peak fitting using the Origin 9.1.0 software (OriginLab Corporation). We used the structural model derived for the pristine SBA-15 sample (for the full derivation, please refer to the original paper ${ }^{\mathrm{S} 1}$ ):

$F(q)=\frac{(\alpha-1) R_{1}^{2} Z\left(q R_{1}\right)-\alpha R_{2}^{2} Z\left(q R_{2}\right)}{(\alpha-1) R_{1}^{2}-\alpha R_{2}^{2}}$ 
where $\alpha$ denotes the electron density ratio between the microporous corona and the dense silica matrix ( $\left.\rho_{1} / \rho_{0}\right)$, while $R_{1}$ and $R_{2}$ are the radii of the (mesopore + corona thickness) and the mesopore, respectively. The function $Z$ is given by $Z(q R)=2 J_{1}(q R) /(q R)$, where $J_{1}$ is the Bessel function of the first kind of first order. Equation 1 can be used to fit the integrated intensities $\mathrm{I}\left(q_{h k}\right)$ corrected with the multiplicity factor $\mathrm{M}_{\mathrm{hk}}$ by minimizing the variance:

$\chi^{2}=\sum_{h k}\left|\left(\left[\frac{I\left(q_{h k}\right)}{M_{h k}}\right]-\left[K|F(q)|^{2}\right]\right)\right|^{2}$

In the fitting, $R_{1}, R_{2}$, and $\alpha$ were allowed to vary, which makes it possible to determine the corona and pore radii, as well as the porosity of the corona $(P=1-\alpha)$. Figure S3b illustrates that the fit of the SBA-15 sample corresponds well to the experimental data points. The fitting gave the following results: $R_{1}=4.2808 \pm 0.00636 \mathrm{~nm}, R_{2}=3.123 \pm 0.00759 \mathrm{~nm}$ and $\alpha=0.54485 \pm 0.00381$. This data made it possible to determine the primary mesopore size $\left(2 R_{2}=6.2 \mathrm{~nm}\right)$, the corona thickness $\left(R_{1}-R_{2}\right.$ $=1.2 \mathrm{~nm})$, and the porosity of the corona $(P=0.46)$. These values correspond well to the ones reported by Zickler et al. ${ }^{\mathrm{S} 1}$ 


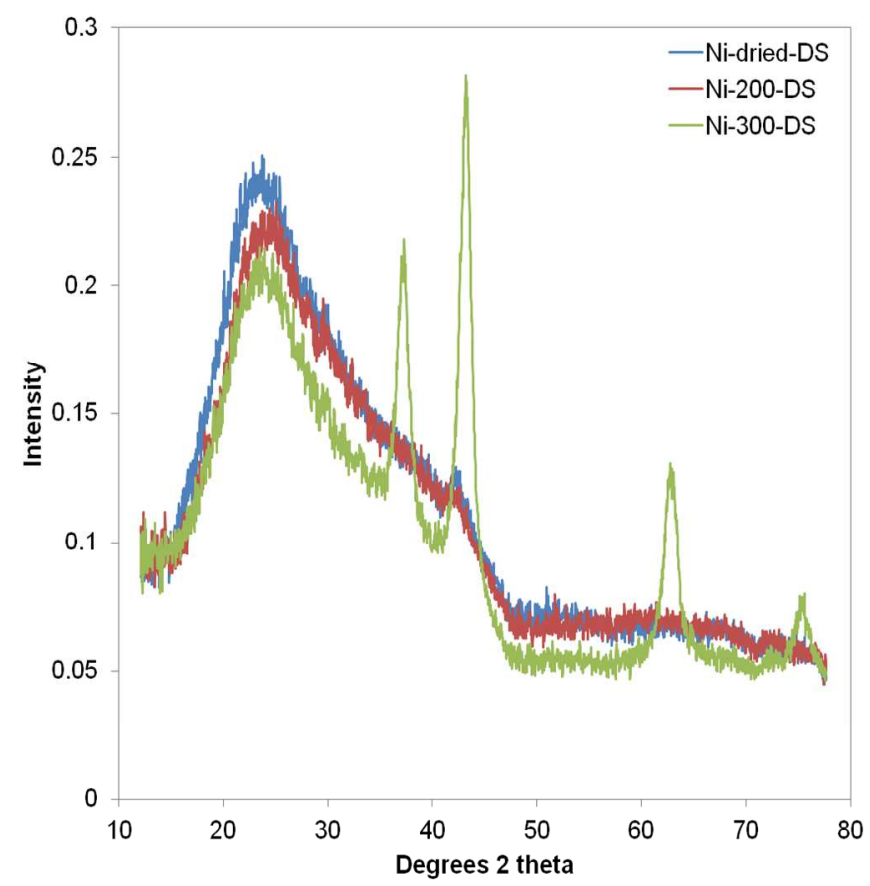

Figure S4. XRD of composite samples infiltrated by the double-solvent method (DS) ${ }^{\mathrm{S} 1}$ and heated at different temperatures. The reflections seen for the Ni-300-DS sample are from NiO (JCPDS card number: 01-089-3080).

When looking more closely at the broadening of the reflections in Figure 1, it appears that the various nickel nitrate salts have sharper reflections than $\mathrm{NiO}$, which could indicate that XRD mainly detects salt crystals from the exterior of the particles. In order to verify this hypothesis, we measured XRD on samples that had been infiltrated by the double-solvent method, which is an efficient technique to selectively fill the pores (Figure S4). ${ }^{\text {S2 }}$ After drying and even after heating at $200{ }^{\circ} \mathrm{C}$, no crystalline peaks could be determined for this sample, indicating that the salt in the pores is either in a liquid or an amorphous form. On the contrary, broad $\mathrm{NiO}$ reflections can be seen after heating at $300{ }^{\circ} \mathrm{C}$. Scherrer

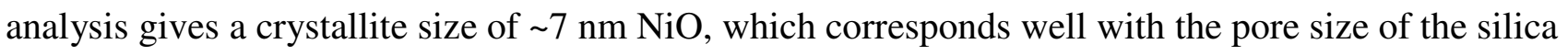
template $(6.8 \mathrm{~nm})$. 


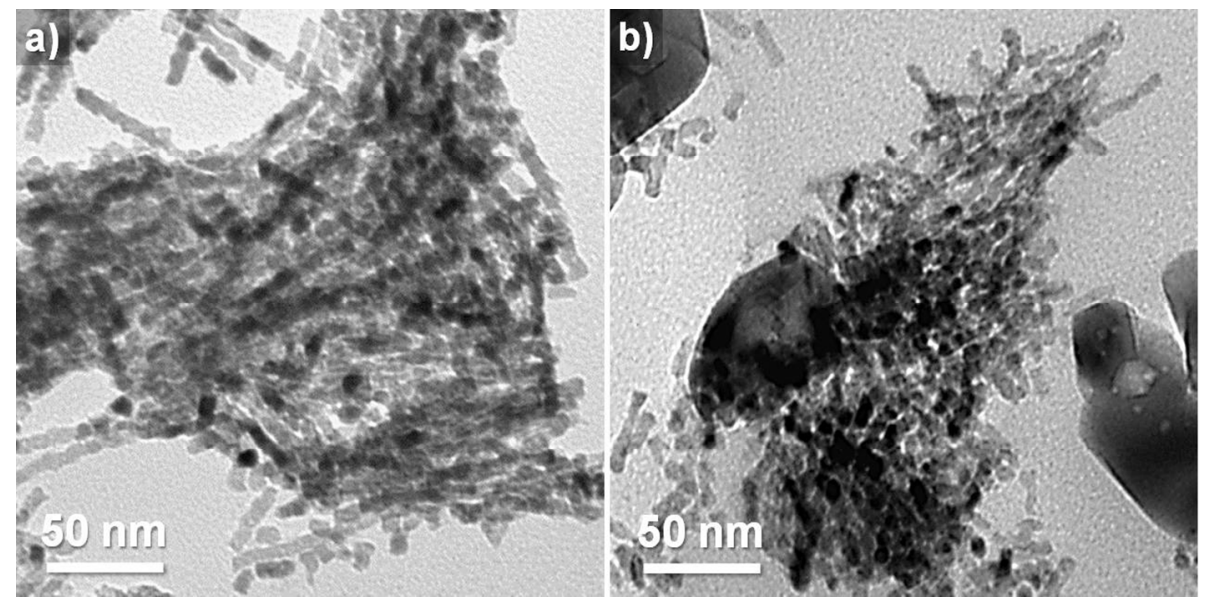

Figure S5. TEM images of a) Ni-500-Air- $R$ and b) Ni-500-He- $R$ replica samples. 


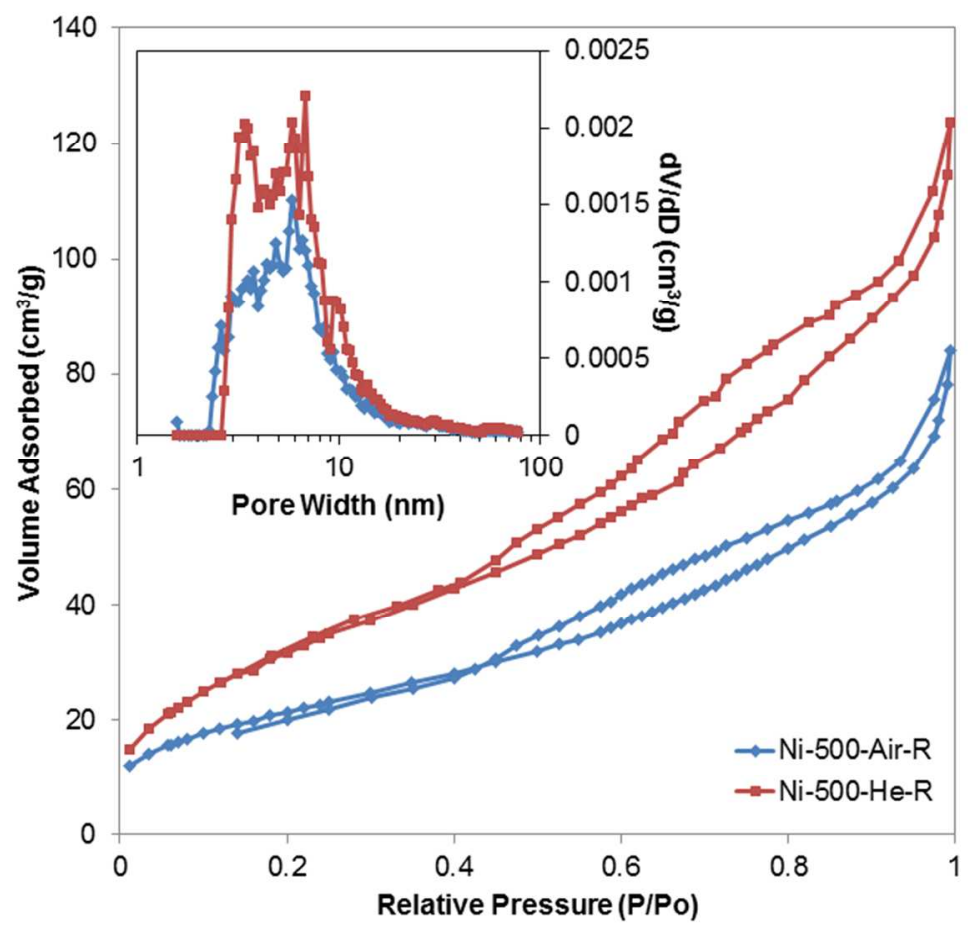

Figure S6. Nitrogen physisorption isotherms of the etched NiO samples (Ni-500-Air-R and Ni-500He-R). Inset: The corresponding NL-DFT pore size distributions.

\section{References}

${ }^{\text {S1 }}$ Zickler, G. A.; Jähnert, S.; Wagermaier, W.; Funari, S. S.; Findenegg, G. H.; Paris, O. Physisorbed Films in Periodic Mesoporous Silica Studied by In Situ Synchrotron Small-Angle Diffraction. Phys. Rev. B 2006, 73, 184109.

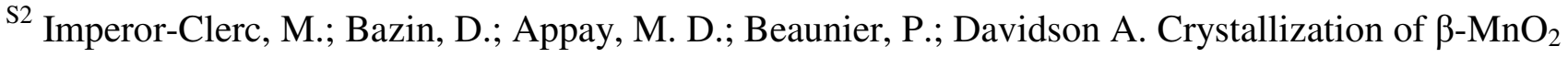
Nanowires in the Pores of SBA-15 Silicas: In Situ Investigation Using Synchrotron Radiation. Chem. Mater. 2004, 16, 1813-1821. 